\title{
The Ethical Significance of Antibiotic Resistance towards Aquaculture Practices
}

\author{
Ahmed Jalal Khan Chowdhury ${ }^{1}$, Akbar John², Dilruba Nasrin ${ }^{3}$, Abdurezak Abdulahi Hashi ${ }^{4}$, Suhaila Mohd \\ Omar $^{4}$, Nur Nazifah Binti Mansor ${ }^{1}$ \\ ${ }^{1}$ Department of Marine Science International Islamic University Malaysia (IIUM), Kuantan, Pahang, Malaysia \\ ${ }^{2}$ INOCEM Research Station, International Islamic University Malaysia (IIUM), Kuantan, Pahang, Malaysia \\ ${ }^{3}$ Centre for Vaccine Development, University Maryland School of Medicine, Baltimore, Maryland, USA. \\ ${ }^{4}$ Department of Biotechnology, Kulliyyah of Science, International Islamic University Malaysia (IIUM), \\ Kuantan.
}

\begin{abstract}
In recent decade, aquaculture species, including fish are under danger from bio-aggressors like viruses, bacteria, parasites and fungi. These organisms harm either spontaneously or through aquatic animal husbandry practices or both. The chemicals employed in aquaculture are drugs like antibiotics used to treat diseases, chemicals introduced through construction materials and hormones used to alter the reproductive viability, sex and growth rates. Drugs used to treat disease are the most dangerous to the fish. These persistent antibiotics tend to increase antibiotic-resistant free-living bacteria, thereby altering the composition of normal marine and freshwater bacterial flora. Evidence suggests that these antibioticresistant organisms in the marine environment will, in turn, pass their antibiotic resistance genes to other bacteria including human and animal pathogens. Antibiotic treatment in aquaculture is achieved by medicated baths and medicated food. In both cases, the probability exists for antibiotics to pass into the environment, affecting wildlife, remaining in the environment for extended periods of time and exerting their antibiotic effects to human. In this manner, potential alterations of the diversity of the marine microbiota produced by antibiotics may alter the homeostasis of the marine environment and affect complex forms of life including fish, shellfish, marine mammals, and human beings. The contamination of surface waters with antimicrobials has become an increasing public health concern because of the emergence of multi-resistant pathogens. Efforts to make progress on these issues require us to raise, confront and enact some difficult ethical decisions that will affect the living standard of human. Nevertheless, excessive antibiotic use in aquaculture should be of high concern to the aquaculture industry and its regulators, to public officials dealing with human and animal health and with the preservation of the environment, and to non-governmental organizations dealing with these issues.
\end{abstract}

KEYWORDS: Aquaculture, antibiotic resistance, horizontal gene transfer

\section{Antibiotic Resistance}

Antibiotic resistance is one of the vital challenges for human medicine and livestock, fisheries and veterinary medicine since last decade. However, there is still a lack of understanding about the reasons and ethical significance of resistance of bacteria against antibiotics in the aquatic environment despite numerous studies. ${ }^{1,2}$ Antibiotic resistance can reach the environment through land run off and accidental discharges in to the water systems that will adversely affect aquatic and terrestrial organisms, which eventually might reach humans through drinking water and food chain by means of food consumption., ${ }^{3,4}$ Lately, the development and spread of antimicrobial resistance have become a global public health problem due to

Corresponding Author:

Professor Dr. Ahmed Jalal Khan Chowdhury

Faculty of Science,

International Islamic University Malaysia,

Jalan Sultan Ahmad Shah,

25200, Kuantan,

Pahang ,Malaysia

Email: jkchowdhury@iium.edu.my its usage in both human and non-human subjects. It is generally documented that any use of antimicrobial agents can lead to the emergence of antimicrobial resistant microorganisms and further promotes the dissemination of resistant bacteria and resistance genes. ${ }^{6}$ Besides that, resistance genes gets genetically transferred and mutated to reach virulence and resistance against commercially available antimicrobials. Thus, the use of antimicrobials in one area, such as in an aquaculture field might get dispersed to another geographically distant area over time.

Numerous biological, behavioral, economic, environmental and social factors contribute to the production and propagation of antimicrobial resistance (AMR). AMR has been pronounced as one of the major threats to individual and population health in the 21st century as discussed by reputable national and international organizations. They have repeatedly highlighted the crucial need for action and has become exclusively a topic for discussion among experts in the medical and microbiological profession. ${ }^{7,8,9}$ Last year, the World Health Assembly (WHA) approved a new global action plan on AMR 
and the topic was discussed as one of the priorities for policy action at a recent G7 meeting. ${ }^{10}$ The move towards a more substantial response may partly be driven by an improved understanding of the consequences of inaction and its ethical implications. The Centers for Disease Control and Prevention estimate that as much as $\$ 20$ billion in direct health care costs and $\$ 35$ billion in lost productivity are associated with AMR to the US economy annually. ${ }^{11}$ A report commissioned by the UK government last year suggested that the death toll of AMR could be as high as 300 million people until 2050, with an estimated total financial loss of up to $\$ 100$ trillion. $^{8}$ While this calculation includes the effect of resistance not just against antibiotics, but also against antiviral drugs, it is certainly indicative of the vast scale and seriousness of the problem. $^{12}$

Due to the enormous importance of antimicrobial drugs in the functioning and delivery of modern health care, the progressive exhaustion of effective antibiotics presents health care professionals and policy makers with a distributive dilemma that raises complex moral questions of justice, especially how to fairly allocate antimicrobial resources ${ }^{11}$. Besides, half of the world's production of antibiotics is still used in animal and fish farming, which has created reservoirs for resistant bacteria and exacerbates the problem. ${ }^{13,14,15}$

\section{Antibiotic Usage in Aquaculture Practices}

Aquaculture activities have shown that high loads of antibiotics in sediments inhibit the growth of bacteria. The fact that the exposure is highly concentrated must also be considered to be critical. The substances used in fish farming can enter sediments directly from water without undergoing any kind of purification process. Some investigations have demonstrated the existence and perseverance of antibiotics applied extensively in fish farming. ${ }^{16}$ It is evident that Fluoroquinolones, sulfonamides and tetracyclines are strongly adsorbed and therefore, they can readily be accumulated in the sediments. It is not clearly known as to what degree and under what circumstances the compounds are effective after absorption or whether they are released to contribute to resistance (Fig. 1).

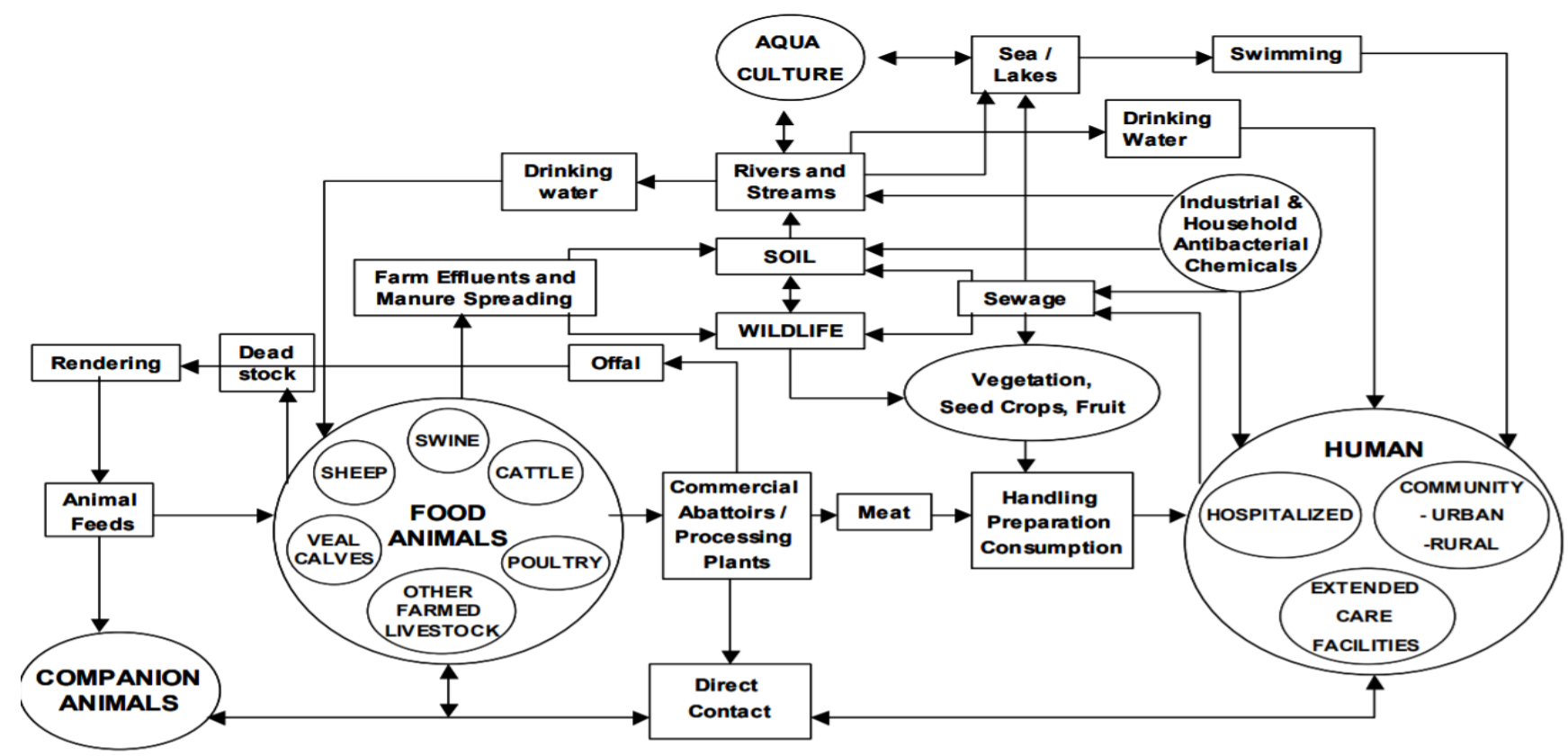

Figure 1: Flow Chart of AMR passes through a different food chain and act as Human Pathogens.

Antimicrobials can have qualitative and quantitative effects upon the resident microbial community in sediments. Increased antibacterial resistance in sedimentary bacteria is often the most sensitive environmental indicator of past antibacterial use. In fact, various patterns of resistance among strains were isolated from very close geographical areas during the same year, suggesting diverse patterns of drug resistance in environmental bacteria within this area. ${ }^{17}$ In addition, the cross-resistance patterns have suggested that the resistance determinants among Vibrio spp. are acquired differently within the sediment and seawater environments. Several research findings have demonstrated the presence of antibacterial residues during aquaculture activities in fish and shrimp farms. ${ }^{18,19}$ In shrimp farming, a large amount of shrimp food and antibiotics have been used to increase production and to protect the shrimp from diseases. Consequently, a large portion of feeds and antibiotics enters the water as wastes, causing hazardous pollution. Recent studies have shown that many antibiotics persist in the sediment and in the aquatic environment for several months following their release into the fish farm. ${ }^{20}$ The residues of antibacterial agents may affect the sedimentary microbial community and introduce antibiotic resistance in the bacteria. ${ }^{21}$ It was observed that individual and multiple antibiotic resistances are associated with antimicrobial use. A study in 
Thailand has indicated that the pattern of antibiotic use among the farms can cause the risk of the development of resistant bacteria strains. Antimicrobial usage in aquaculture can result in residues of antimicrobials in aquaculture products which can present a hazard to public health if the consumer becomes exposed to the residues, either through the consumption of aquaculture products or by handling it. Besides that, it is also used in aquaculture as prophylactics, growth promoter and to decrease the incidence of illnesses. In the fishfarming sector, the widespread use of antibiotics for treating bacterial diseases is associated with the development of antibiotic resistance; such as Aeromonas hydrophila, Aeromonas salmonicida, Edwardsiella tarda, Edwardsiella icttaluri, Vibrio anguillarum, Vibrio salmonicida, Pasteurella poolside and Yersinia ruckeri. ${ }^{22}$ Thus, the correct dosage of antibiotics should be given to the fish and shrimp aquaculture to avoid the release of excess residues of antibiotics. The inappropriate dosing will not succeed to kill the disease agents completely and furthermore, promote growth of the most resistant strains, which may later develop hard-totreat disorders. This is due to the fact that most commercial antibiotics has been chemically altered in the laboratory to improve their potency or to increase the range of species they affect. With the increasing importance of the aquaculture industry and increasing consumption of products of aquaculture, human exposure to resistant bacteria and resistance genes in aquaculture products also increases through professional activities or food handling. This type of exposure also represents a potential route for the spread of resistant bacteria and resistance genes from aquaculture products to humans.

\section{Ethical Issues in Aquaculture Production}

In the cases of disease and treatment, personnel safety might arise as a main concern. There is evidence that some fish pathogens can be contagious to the people involved in aquaculture practices. Some of the current ethical challenges faced include -focusing on three broad questions: (i) why AMR is an ethical issue, (ii) what specific moral questions it raises and (iii) how we should broadly approach the ethical issues raised by AMR. The consumers' safety-wellbeing issues refer mainly to aquaculture-derived microbes and biotoxins. Another principle aspect is the occurrence of chemicals used in aquaculture therapeutic processes. The use of antibacterial dictates a withdrawal period to ensure consumer safety, e.g., to allow antibiotics presence to reduce below the maximum residue level (MRL) according to the European legislation. However, it is suggested that the withdrawal periods should be determined for each drug, each target species, and at different temperature conditions, in order to ensure that no residues exist in the edible tissues of farmed products. Besides, the similar studies have shown that antibacterial used in aquaculture has also been related to the development of resistance of human pathogens and therefore to higher vulnerability might enhance potential human disease outbreaks. Some reviewed cases of pathogens that have been introduced to new geographical areas through aquaculture in the inland waters. ${ }^{23}$ Environmental pollution by chemotherapy includes the residues and persistence in the aquatic environment due to uneaten medicated feed, unabsorbed and unmetabolized drug release. It has been observed that often antibacterial drugs have not been used with proper accountability in the aquaculture industry, thus significant quantities of drugs are released into the vicinity of fish farms creating environmental disaster. These drugs can be transferred, make complexes in the water column, accumulate in the sediment and taken up from non-target organisms including scavengers and secondary aquaculture species (i.e., Wild species that gather around the aquaculture installations) such as crabs, mussels, and certain fish species. The inhibition of certain microorganisms and the generation of antibiotic resistant strains of microorganisms raise the issue of environmental autonomy violation. In addition, the development of antibiotic resistance by bacteria can lead to an increase of diseases and difficulty in effectively treating them.

Furthermore, toxic effects in aquatic organisms have been mentioned from aquaculture-used chemotherapeutics. ${ }^{24}$ Thus environmental wellbeing is also degraded. The use of antimicrobial agents in aquaculture is in principle good for the aquaculture organism, however is questioned with respect to the right of receiving the proper therapy. Thus, since responsibility occurs for the reduction of their health status, this also creates obligations for prophylactic (e.g., vaccinations, immunestimulants) and therapeutic measures.

Impact of Antibiotic Resistance on Human Health It has been broadly understood that the bacteria and other microorganisms that often cause infections are known to be remarkably resilient and have the ability to develop ways for surviving drugs that are meant to kill or weaken them. Recent scientific evidence suggests that during the last decade, antibiotic resistance by various mechanisms has increased worldwide in bacterial pathogens leading to treatment failures in human and animal infections. Though the resistance against different types of biocides (including disinfectants, antiseptics, preservatives, sterilants) has been studied and characterized ${ }^{25}$, only limited sound scientific evidence to correctly assess the risks of antibiotic resistance induced by resistance to biocides is available. ${ }^{26}$ Furthermore, research indicates that antibiotics may share some common behaviors and properties in their respective activity and in the resistance mechanisms developed by bacteria. Salmonella spp. and $E$. coli strains, including resistant strains, can be found in aquatic environments as a result of contamination with such bacteria from human, animal or agricultural environments.

The resistance is caused by the usage of 
antimicrobials in humans and in terrestrial animals. Sewage contamination or runoff from agricultural areas with grazing animals to aquaculture operations can result in the presence of resistant Salmonella spp. and $E$. coli in products of aquaculture. The similar picture applies to Shigella spp, which is strictly human pathogen; antimicrobial usage in humans is the promoter of resistance development and spread in this species. In some aquaculture environments, human pathogens deriving from terrestrial animal or human wastes may be incapable of extensive cell division limiting the extent to which usage of antimicrobial agents in aquaculture can exert a selective force for the emergence of resistant variants. However, in some climates and aquaculture systems, there might be cell division and usage of antimicrobial agents in aquaculture can exert selective pressure for the emergence of resistant variants.

Vibrio spp. are marine bacteria of which some can be pathogenic to humans. Resistance in Vibrio cholerae and Vibrio parahaemolyticus can be a result of human usage of antimicrobials. But may also be a consequence of the use of antimicrobials in aquaculture. The risk that resistant bacteria from aquaculture may be present in treated drinking water supply is remote. In areas where drinking water is not treated, resistant bacteria from aquaculture may reach drinking water supply. ${ }^{27}$

\section{Prevalence of Antimicrobial Resistance Genes}

It is well documented that antimicrobial resistance develops and spreads in fish pathogens as a consequence of exposure to antimicrobials. Available literature shows that resistance is widespread in fish pathogens and, in general, that resistance is more prevalent where the usage is high. The resistance genes in fish pathogens are often the same as those found in human pathogens, and most of these genes are transferable. Thus, fish pathogens act as a reservoir of resistance genes that can be transmitted horizontally to human pathogens through different pathways. ${ }^{28}$ Transfer of $\mathrm{R}$ Plasmid and emergence of new drug resistance gene cassettes has been reported in human and fish pathogenic bacteria in aquatic environments. Antimicrobials used in aquaculture deposited in the environment has the potential for a selective pressure on environmental bacteria. As a result, there is also potential for the establishment of a reservoir of resistance genes for further dissemination, which could ultimately reach humans. Although antibiotic usage has clearly benefited the animal industry and helped provide affordable animal protein for the growing human population, the use of antibiotics in food production has also contributed to the emergence and spread of multiple antibiotic resistance (AMR). ${ }^{29}$ Along with antibiotics used in human medicine, the use of antibiotics for animal treatment, prophylaxis and growth promotion exert an immeasurable amount of selective pressure toward the emergence and propagation of resistant bacterial strains. Animals can serve as mediators, reservoirs and disseminators of resistant bacterial strains and/or AMR genes. ${ }^{30}$ Consequently, imprudent use of antimicrobials in animals may eventually result in increased human morbidity, increased human mortality, reduced efficacy of related antibiotics used for human medicine, increased health care costs, increased potential for carriage and dissemination of pathogens within human populations and facilitated the emergence of resistant human pathogens. ${ }^{31}$ Huijbers, Huijbers, P.M.C. (2016). (Figure 1).

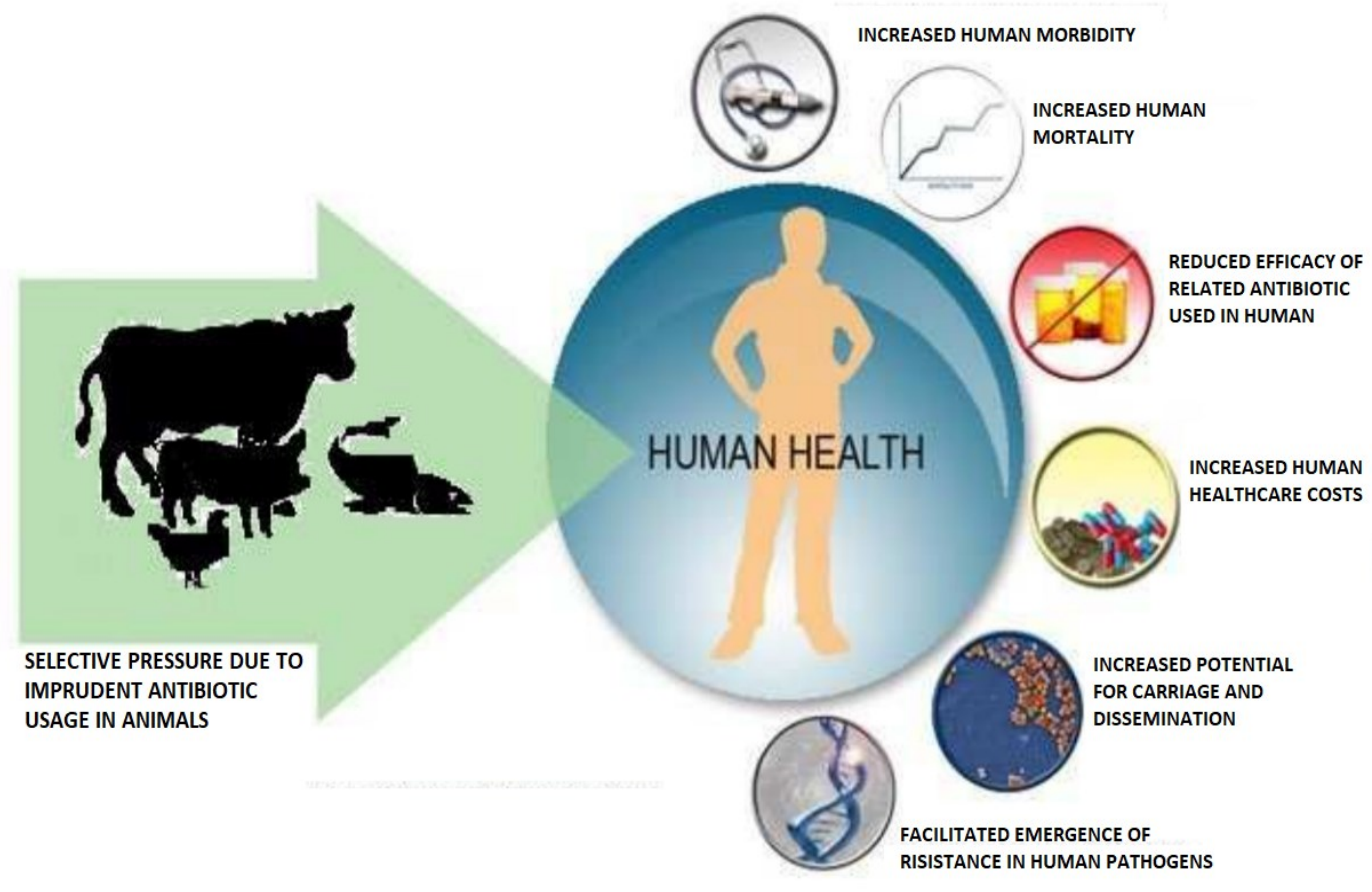

Figure 2 : Human Health Impact of Antimicrobial Resistance in Animal Populations (Huijbers, 2016) 
Ethics in Antimicrobial Resistance

Antimicrobial resistance arises as a result of the complications of treating infectious diseases; it is a complex, multifaceted global challenge that affects the environment, human and animal health, agriculture and the economy. Due to the intensive utilization by a multitude of persons, institutions and society's antimicrobial resistance impacts, it presents a distinct and significant ethical issue globally. Antimicrobial resistance is driving current and future populations at significant risk of injury, loss and death. This will include questions about who is morally responsible for this problem and whether attributions of blame or sanctions should be apportioned and who should bear the costs of this problem. It is also going to require us to shape the institutional structures and individual behaviors of governments, corporations, scientists, clinicians and patients, which raise questions about important moral values such as solidarity, liberty, privacy, reciprocity, fairness and the common good. It is worth exploring some of the life-threatening issues that make antimicrobial resistance a moral issue, and the problem of AMR requires recognition of its ethical implications and their need to be addressed as it is a part of universal problem.

The threat of progressing drug resistance puts us at a tangible risk of harm in our lifetime, and our failure to control and reduce AMR will impose risk on other people and on future generations. ${ }^{32}$ The scope of this problem is perhaps easiest to illustrate by the repeated and growing number of warnings by experts in global health and microbiology, who predict the dawn of a post-antibiotic era, should we fail to act quickly and decisively. ${ }^{33}$ While models that predict the impact of the AMR on future morbidity and mortality are-by their naturespeculative and depends on a large number of uncertain variables, there appears to be broad consensus among experts that the effects of AMR are likely to be catastrophic in the near future, if we fail to take appropriate action. ${ }^{34}$

AMR will not only render the treatment of acute bacterial infections more difficult and costly-it will also increase the risk for medical procedures in which antibiotics are used prophylactically, such as surgical interventions or some types of chemotherapy. In addition, AMR drastically increases the risk of a return of epidemic and pandemic outbreaks that could be treated with antibiotics in the past. ${ }^{35}$ In fact, we are facing high levels of morbidity and mortality due to multi drug-resistant and extensively drug-resistant tuberculosis, with drugresistant typhoid infections becoming more and more common as well. ${ }^{36}$ It is, however, not only the magnitude of the risk that current and future generations are faced with that creates ethical problems. Due to the speed and scale with which we must react in order to avert a post-antibiotic age, we are also faced with what constitutes a proportional response and, crucially, who bears responsibility to act. $^{37}$ While AMR is a complex challenge with numerous causes, it is the broad use of antimicrobials in health care and agriculture that is the driving force behind the emergence of drug resistance utilized in Pharmaceutical industry.

However, recognizing the large part that we are involved in the emergence of AMR also indicates that we should think seriously about the accountability for the emergence of drug resistance. If the preservation of effective antimicrobials is in the interest of current and future generations, and indeed their lives depend on it, then we should also identify the people and need to be sanctioned for the ignorant, unnecessary or wrongful use of antibiotics, or any other practice that is likely to hasten the emergence of AMR. ${ }^{38}$ This may mean that we will be morally justified in imposing greater burdens or costs for their contribution to the current state of AMR. At the same time, however, we must remember that there may be no truly sustainable way of using antibiotics in the long-run, as micro-organisms have shown to be almost infinitely adaptable since the first introduction of antibiotics. This means that we struggle to keep abreast of AMR will most likely be a continuous and a malicious cycle of resistance and obsolescence. ${ }^{39}$ While this does not absolve current generations of their responsibility for their inappropriate use of antibiotics, it should make us reconsider what kind of policy problems AMR represents. If it is not easily solvable, then our moral obligations to future generations may not so much be to fix but rather to manage the problem. Understanding AMR as a slowly emerging disaster highlights a number of ethical and legal challenges that will become increasingly severe. ${ }^{40}$

Islamic teachings promote the importance of health. The Islamic teachings on health preservation include two interrelated aspects; first Islam commands its adherents to maintain healthy life style in terms of eating quality food and beverages, so that the person's immune system is strengthened and thus diseases are prevented. There are a number of Prophetic narrations in which he recommended eating certain types of food such as honey ('asal), olive oil (zayt zaitūn), and black seeds (habah alsawdā'), and etc, as a form of strengthening the body's resistance. ${ }^{41}$ Secondly, Islam also commands its adherents to seek medical treatment for "God never inflicts a disease without providing a cure for it." This is so because, for "He who put diseases on earth, has also put its remedy there". ${ }^{42}$ Therefore, health preservation is part and parcel of the Islamic teachings. With regards to the antibiotics resistance of the body, Muslim jurists normally seek clarification from the relevant scientists to explain the effect of given scientific activities in poultry and animals resource affect negatively on human health or otherwise. If any given activity in animal feeding risks the health of its consumers, then Islamic scholars require such activity to be addressed duly, and if need stopped. It is well recognized that the issues of antimicrobial use in food animals are of global concern. International interdisciplinary cooperation is essential, and FAO, 
OIE and WHO have organized a number of consultations to address the issues related to antimicrobial use, the emergence of resistant pathogens and the potential public health impact. ${ }^{43}$

\section{CONCLUSION}

Antimicrobial resistance in human pathogens is largely the consequence of use in human medicine and terrestrial animal agriculture. While difficult to assess in aquaculture the relative risk to humans is likely to be lower. The existing literatures did not thoroughly address the use of antimicrobials in aquaculture and the public health impact of such use in Southeast Asian countries, which are highly developed in aquaculture activities. Nevertheless, large quantities of antimicrobials are used in aquaculture in some countries, often without professional consultation or supervision. Furthermore, an important proportion of aquatic animals raised for the global aquaculture industry are raised in countries with insufficient regulations and limited enforcement for the authorization of antimicrobial agents used in animals. In some countries the availability of registered antimicrobials is insufficient which contributes to illegal use. The public health hazards related to antimicrobial use in aquaculture include the development and spread of antimicrobial resistant bacteria and resistance genes, and the occurrence of antimicrobial residues in products of aquaculture. The greatest potential risk to public health associated with antimicrobial use in aquaculture is thought to be the development of a reservoir of transferable resistance genes in bacteria in aquatic environments from which such genes can be disseminated by horizontal gene transfer to other bacteria and ultimately reach human pathogens.

\section{ACKNOWLEDGEMENT}

The authors are grateful to Research Management Centre (RMC), International Islamic University Malaysia (IIUM) for partially funding this research project entitled "Fisheries Conservation Towards Sustainable Development in Tropical Environment" through Research Grant (RIGS16-106-0270) during their study period.

\section{REFERENCES}

1. Kümmerer K. Antibiotics in the aquatic environment - A review - Part I. Chemosphere 2009;75: 417-434.

2. Kümmerer, K. Antibiotics in the aquatic environment - A review - Part II. Chemosphere 2009b; 75:435-441.

3. Edquist LE and Pedersen KB. Antimicrobials as growth promoters: resistance to common sense. In: Harremoës, P. (Chairman), Gee, D. (EEA Ed.), MacGarvin, M. (Executive Ed.), Stirling, A., Keys, J., Wynne, B., Guedes Vas, S. (Eds.), Late lesson From Early Warnings: The Precautionary Principle 1896-2000. Environmental Issue Report No. 22, European
Environment Agency, Copenhagen, 2001; 93109.

4. Prior LSOS. The Garrod Lecture: Antimicrobial resistance-animals and the environment. Journal of Antimicrobial Chemotherapy 2008;62(229-233).

5. Aarestrup FM, Wegener HC and Collignon P. Resistance in bacteria in the food chain: epidemiology and control strategies. Expert Review of Anti-Infective Therapy 2008; 6 (5):733-750.

6. OIE FAO Organization International des Epizooties (World Organisation for Animal Heath), World Health Organization, and Food and Agriculture Organization of the United Nations, Joint FAO/OIE/WHO 1st Expert workshop on non-human antimicrobial usage and antimicrobial resistance: scientific assessment. Geneva, Switzerland, 1-5 December 2003. 2004a; http:// www.who.int/foodsafety/publications/micro/ en/report.pdf

7. Davies SC and Gibbens N. UK Five Year Antimicrobial Resistance Strategy 2013-2018. 2013; London: Department of Health.

8. World Economic Forum. Global Risks 2013 Insight Report Eighth Edition. Geneva: World Economic Forum, 2013.

9. O'Neill J. Review on Antimicrobial Resistance: Antimicrobial Resistance: Tackling a Crisis for the Health and Wealth of Nations 2014; London: Wellcome Trust.

10. Littmann J, Viens, AM The Ethical Significance of Antimicrobial Resistance. Public Health Ethics. 2015;8(3):209-224.

11. Centers for Disease Control and Prevention. Antibiotic Resistance. Threats in the United States 2013. Washington: CDC.

12. Littmann J. Antimicrobial Resistance and Distributive Justice. London: University College (PhD dissertation) 2014.

13. Health Protection Agency. Overview of Antimicrobial Usage and Bacterial Resistance in Selected Human and Animal Pathogens in the UK: 2004; A Joint Report. Communicable Disease Surveillance Center Northern Ireland, Food Standards Agency, London, Health Protection Agency, Veterinary Laboratories Agency.

14. Food and Drug Administration. The Judicious Use of Medically Important Antimicrobial Drugs in Food-Producing Animals. Rockville, MD: U.S. Department of Health and Human Services; 2010.

15. Bengtson B, Greko C. Antibiotic ResistanceConsequences for Animal Health, Welfare, and Food Production. Uppsala Journal of Medical Sciences 2014; 119:96-102.

16. Jalal KCA. Akbar John, B. Kamaruzzaman B.Y. and Kathiresan K. Antibiotic resistant bacteria - a continuous challenge in the new millennium Edited by Marina Pana. Published In Tech Croatia 2012;143-158.

17. Kümmerer K. Significance of antibiotics in the environment. Journal of Antimicrobial 
therapy; 2003;52:5-7.

18. Landers TF, Cohen B, Wittum TE et al. A

Review of Antibiotic Use in Food Animals:

Perspective, Policy, and Potential. Public

Health Reports, 2012; 127(1):4-22.

19. Weston DP. Environmental considerations in the use of antibacterial drugs in aquaculture. In: Baird D, Beveridge M, Kelly L, Muir J, editors. Aquaculture and Water Resources Management. Black-well Science 1996:140-65.

20. Environment Justice Foundation (EJF). Risky Business: Vietnamese Shrimp Aquaculture Impacts and Improvements. London, UK7 Environmental Justice Foundation 2003; 44.

21. Miranda CD, Zemelman R. Bacterial resistance to oxytetracycline in Chilean salmon farming. Aquaculture 2002;31-47.

22. McPhearson RM, DePaola A, Zywno SR, Motes $\mathrm{Jr}, \mathrm{ML}$, Guarino, AM Antibiotic resistance in Gram-negative bacteria from cultured catfish and aquaculture ponds. Aquaculture 1991; 203 $-211$.

23. Serrano PH. Responsible use of antibiotics in aquaculture. In: Food and Agriculture Organization (FAO) Fisheries Technical Paper 2005; 469:97.

24. De Silva SS and Turchini GM. Towards Understanding the Impacts of the Pet Food Industry on World Fish and Seafood Supplies. J Agric Environ Ethics, 2008; 21: 459.

25. Boucher HW, Talbot GH, Benjamin DK, et al. $10 \times$ '20 Progress - Development of new drugs active against Gram-Negative Bacilli: An update from the infectious diseases Society of America. Clinical Infectious Diseases, 2013; 56, $1685-1694$.

26. Russell AD. Mechanisms of bacterial resistance to biocides. International Biodeterioration \& Biodegradation 1995;36:247-265.

27. SCENIHR. Scientific Committee on Emerging and Newly Identified Health Risks. Assessment of the Antibiotic Resistance Effects of Biocides. European Commission. 2009.

28. Neela, F., Nonaka, L., Rahman, M. and Suzuki, S. Transfer of the chromosomally encoded tetracyclin resistance gene tet $(M)$ from amrine bacteria to; Escheria coli and; Enterococcus faecalis. World Journal of Microbiology and Biotechnology 25, 10951101.

29. Tarr, H.L.A., and Deas, C.P., Antibiotics in Food processing. Experimental preservation of fish and beef with antibiotics. J. of Agriculture Food Chemistry. 1954. 2:372-375.

30. Schmidt, A.S., Bruun, M.S., Dalsgaard, I., Pederson, K. and Larsen, J.L. Occurrence of Antimicrobial Resistance in Fish-Pathogenic and Environmental Bacteria Associated with Four Danish Rainbow Trout Farms. Applied Environmental Microbiology. 2000. 66, 49084915.

31. Huijbers, P.M.C. (2016). Transmission of antibiotic resistance from animals to humans: Broilers as a reservoir of ESBL-producing bacteria. PhD thesis, Wageningen University,
Wageningen, the Netherlands

32. USEPA : Environmental and Economic Benefit Analysis of Final Revisions to the National Pollutant Discharge Elimination System Regulation and the Effluent Guidelines for Concentrated Animal Feeding Operations. EPA 821-R-03-003. 2002. USEPA Office of Water, Washington, DC.

33. Hernandez SP. Responsible use of antimicrobials in aquaculture. FAO Fisheries Technical Paper, 2005; No. 469, FAO, Rome, Italy.

34. Davies SC, Grant J and Catchpole M. The Drugs Don't Work: A Global Threat, 2013; Penguin Specials. London: Penguin.

35. Smith R and Coast J. The True Cost of Antimicrobial Resistance. British Medical Journal 2013: 346, f1493.

36. Cars O, Högberg LD, Murray M et al. Meeting the challenge of antibiotic resistance. British Medical Journal 2008; 337, a1438.

37. Gandhi NR, Nunn P, Dheda K, et al. Schaaf H. S., Zignol M., van Soolingen D., Jensen P., Bayona J. 2010. Multidrug-Resistant and Extensively Drug-Resistant Tuberculosis: A Threat to Global Control of Tuberculosis. The Lancet, 375; 1830-1843.

38. Cars O and Nathan C. Antibiotic Resistance Problems, Progress, and Prospects. New England Journal of Medicine, 2014; 371:17611763.

39. Spellberg B, Bartlett JG and Gilbert DN. The Future of Antibiotics and Resistance. New England Journal of Medicine 2013; 368:299302.

40. Littmann J, Buyx A, Cars O. Antibiotic Resistance: An Ethical Challenge. International Journal of Antimicrobial Agents, 2015; 46(4):359-361.

41. Ibn Qayyim al-Jawziyyah, Mohd b. Abi Baker: Al-Ṫibb al-Nabawiyi. 2008. Cairo: Dār alHadīth.

42. Al-Zahabi, Mohd b. Ahmad: Al-Tibb alNabawiyi. 1989. Cairo: Maktabah al-Qur'an.

43. FAO/OIE/WHO. The Joint FAO/OIE/WHO 2nd Workshop on Non-human Antimicrobial Usage and Antimicrobial Resistance took place in Oslo, Norway, from 15-18 March 2004. Executive Summary- Page 2. 